\title{
EFFECT OF STEP HEIGHT ON THE AERATION EFFICIENCY OF CASCADE AERATOR SYSTEM USING PARTICLE IMAGE VELOCIMETRY
}

\section{A. Azman', M. H. Zawawi' ${ }^{2}$ N. H. Hassan², A. Abas ${ }^{1 *}$, N. A. Razak ${ }^{3}$, A. Z. A. Mazlan ${ }^{1}$ and Mohd Remy Rozainy M.A.Z ${ }^{4}$}

\author{
${ }^{1}$ School of Mechanical Engineering, Engineering Campus, Universiti Sains Malaysia, \\ Penang \\ ${ }^{2}$ Department of Civil Engineering, College of Engineering, Universiti Tenaga Nasional, \\ Selangor \\ ${ }^{3}$ School of Aerospace Engineering, Engineering Campus, Universiti Sains Malaysia, \\ Penang \\ ${ }^{4}$ School of Civil Engineering, Engineering Campus, Universiti Sains Malaysia, Penang \\ *Email: aizatabas@usm.my
}

\begin{abstract}
Aeration is an important parameter in water filtration system as it allows the transfer of oxygen to water through turbulence effect which subsequently increases air entrainment in the water. For water treatment application, aeration efficiency is measured to ensure continuous re-oxygenation of the unfiltered water. Aside from aeration, this paper also studies the flow patterns through the use of particle image velocimetry (PIV) setup. Through the use of real scale down physical model laboratory study is performed using PIV to obtain the velocity profile. These velocity profiles will then be used to calculate the aeration efficiency of the water in a cascade aerator system. Based on the findings, the aeration efficiency obtained from the PIV experiment has a maximum value at the lowest point of the cascade aerator system with a value of 0.0139 due to increase in mass flow rate as it moves through the steps with velocity of $0.418 \mathrm{~m} / \mathrm{s}$. Therefore, in the design of a cascade aerator system, it is advisable to increase the number of steps since it will increase the aeration efficiency of the system.
\end{abstract}

Keywords: PIV, Aeration, Cascade aerator, water treatment, water filtration.

\section{INTRODUCTION}

Cascade aerator is often linked with the stepped spillway system due to its similar configurations and purposes. As an application of the stepped spillway which high potential air-water gas exchangers [1], cascade aerator is used for in-stream re-aeration and it is widely used in water treatment plants to enhance the air-water transfer of atmospheric gasses and the removal of iron and manganese which can cause unpleasant taste and odors. In a nutshell, the basic idea of a cascade aerator is to generate aeration which is extremely helpful in facilitating the transfer of gas into or out of the water. The typical design of a cascade aerator is shown as in Figure 1 below. 


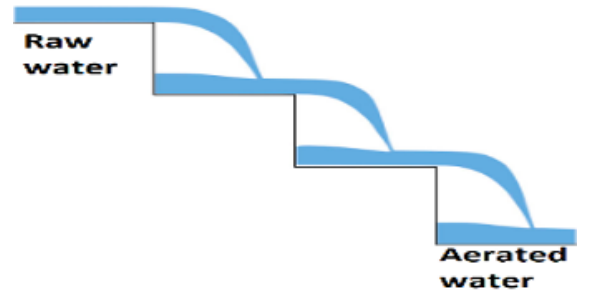

Figure 1: Cross-sectional side view of cascade aerator [1]

Various studies have been concerted to improve the performance of cascade aerator system. In a study by Amador et al, PIV method is used to compute the fluctuation in velocity that is expressed in terms of root-mean square (rms) of the instantaneous velocities. The group found that the maximum values are found to be near to the pseudobottom [2]. In another study, velocity fields were measured by Large Scale Particle Image Velocimetry (LSPIV) and the results showed that relative flow velocity is slightly higher for greater spillway size [3]. Air water flow properties comprise of the comparison in interfacial velocity, bubble count rate and turbulence intensity between the two spillways with different slopes. The comparative analysis proposed that smaller residual energy (better energy dissipation) happens at pooled stepped spillway with slope of $8.9^{0}$ [4]. Another study also prove that the capabilities of PIV indicates velocity fields and profiles were highly organized although velocity of rotating impeller was high [5]. In addition, the velocity distributions inside and outside of droplet were measured and result showed that a pair of symmetrical vortices existed during droplet formation process in their experimental work [6]. In this work the aerator efficiency was obtained based on the step height of cascade aerator.

\section{METHODOLOGY}

\section{Modelling of Cascade Aerator}

A river bank model was drawn with the aid of powerful and easy-to-use Solidworks 3D CAD software. The individual parts of the river bank with exact dimensions were formed by considering the complexity of the geometry. The river bank model is then created via Solidworks and fabricated as shown in Figure 2 below.

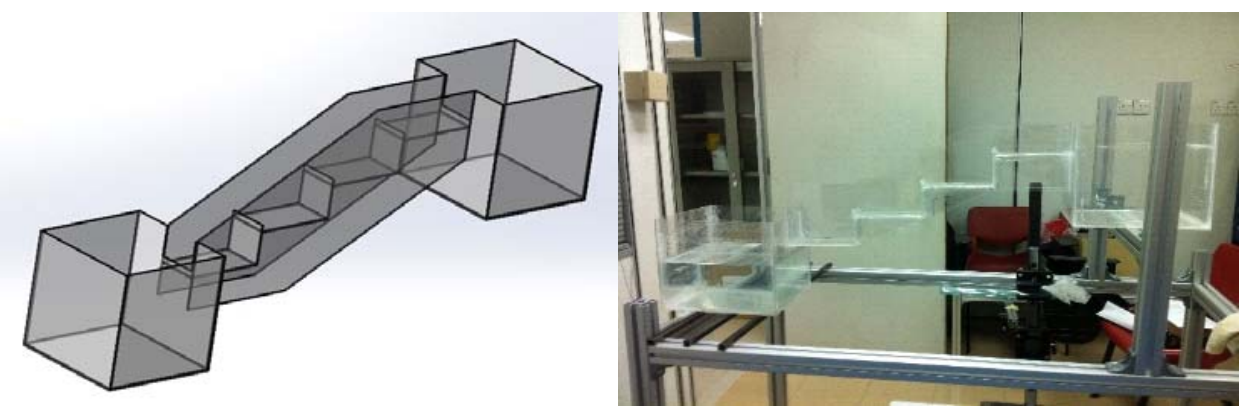

(a)

(b)

Figure 2: (a) CAD model Configuration of set 1 model with barrier height 10mm, (b) Fabrication of the Model

\section{Experiment Setup}


The measurement of water velocity could be done using PIV illumination system which is an optical method to determine the instantaneous vector measurements in cross section flow. Velocity vector of the fluid is calculated and determined from the movement of the tracer particle between two light pulses:

$$
V=\frac{\Delta x}{\Delta t}
$$

where $\Delta \mathrm{x}$ is the displacement of a marker, located at $\mathrm{x}$ at time $\mathrm{t}$, over a short time interval $\Delta$ t separating observations of the marker images. Therefor the changes of velocities can be compute with frame by frame. The video will extract as picture frame by frame and then transfer to PIVlab

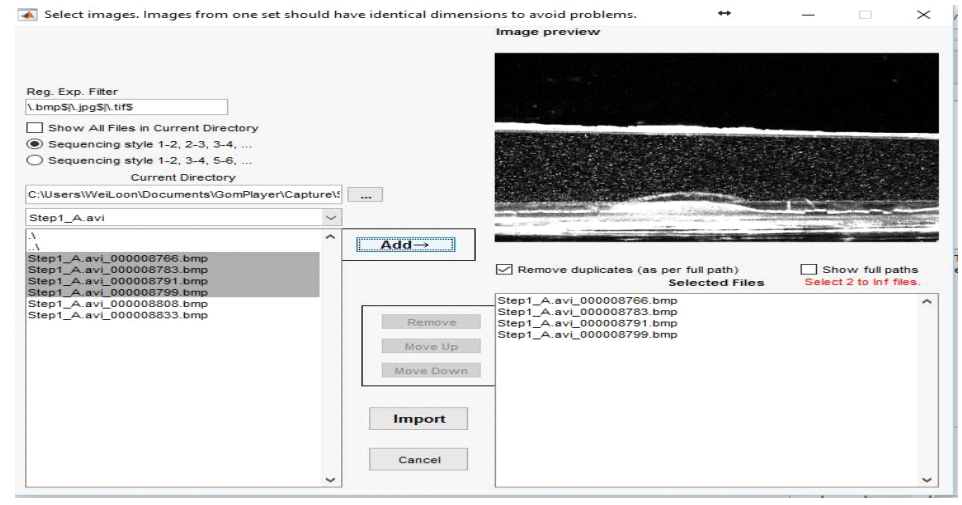

Figure 4: Importing of images to be used in the screen panel of PIVlab

Several crucial materials and instruments would have to be prepared and then set up properly before the carrying out the experiment. The above-mentioned apparatus is then installed properly and the actual arrangement of apparatus for two different configurations of river bank model are shown in Figure 5.

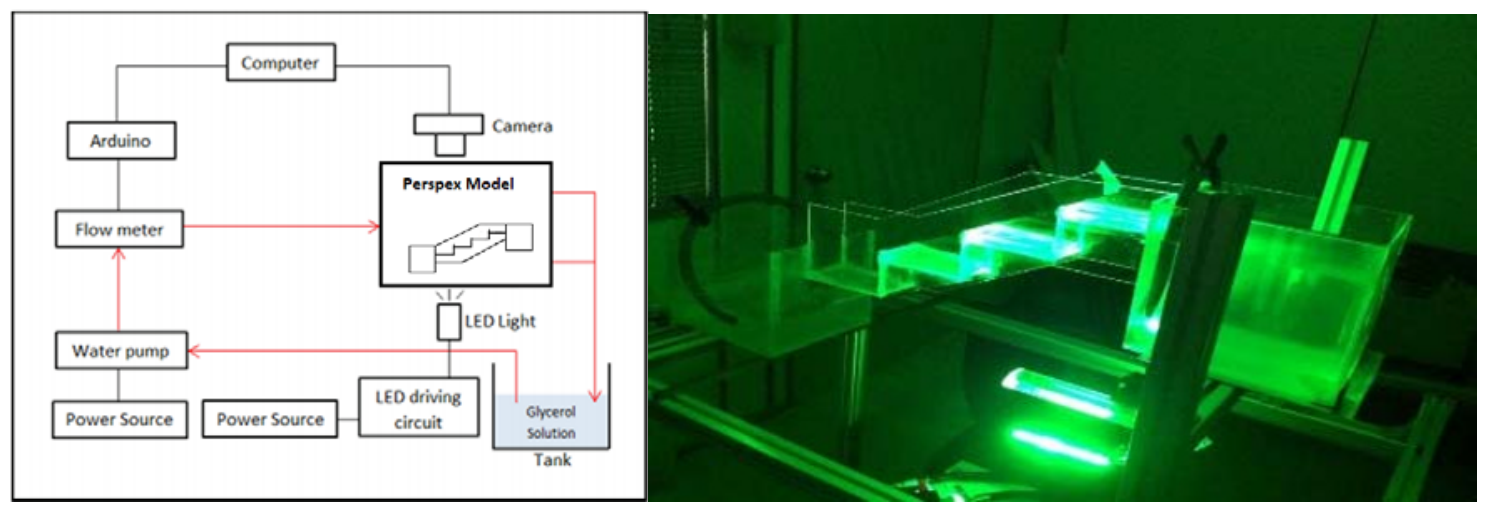

(a)

(b)

Figure 5: (a) Schematic Diagram of experiment setup (b) Actual experimental setup for model with interior lighting being turned off

\section{RESULTS AND DISCUSSION}

The visual investigations of the flow patterns included the observations of the water flow patterns for all river bank configurations for one specific discharge rate. The 
configuration exhibits a nappe flow regime as depicted in Figure 6 with typical flow patterns of free-falling jets from one step to the next step. Snapshots of the simulated flow patterns are shown in Figure 7 which illustrates the velocity vector profile.

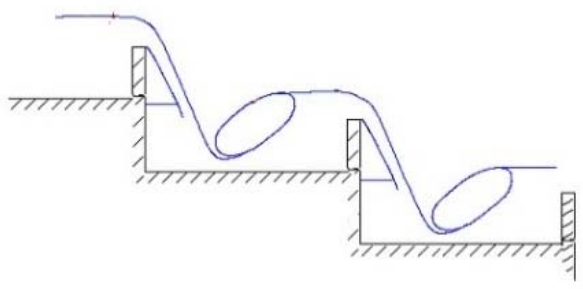

Figure 6: Flow over pooled stepped cascade

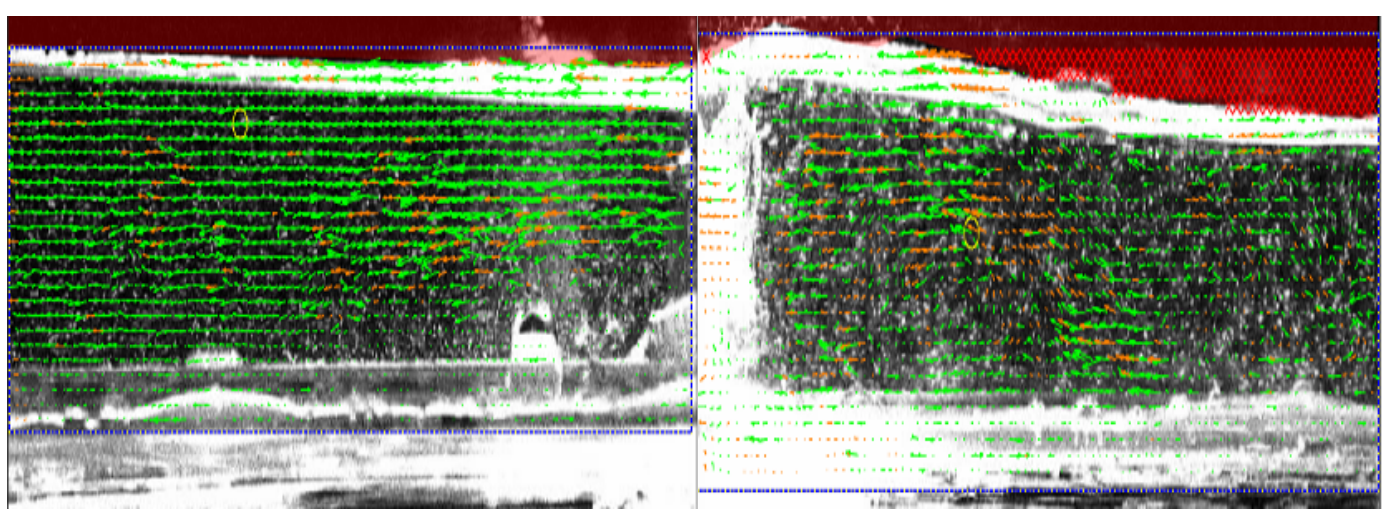

(a)

(b)

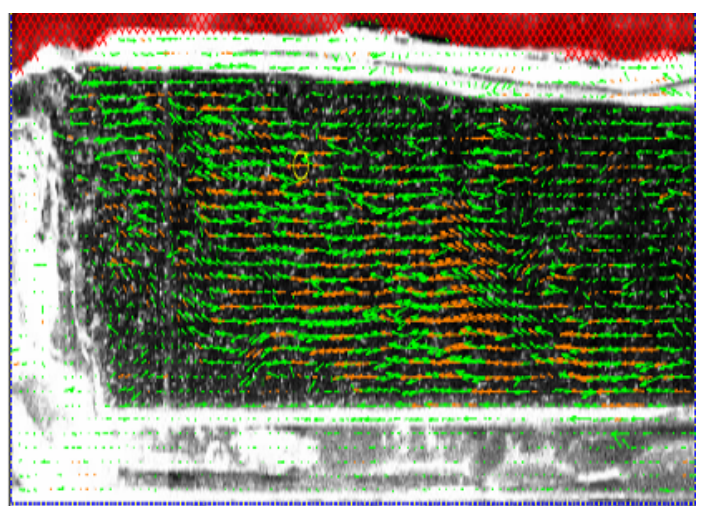

(c)

Figure 7: PIV flow profiles across different steps for (a) First step (b) Second step, (c) Third step

PIV experiment compute velocity variations across the different stepped spillway level. The extraction of velocity values from experimental setup is done using PIVlab via the cross-relation conducted on the image data. A total of four different locations will be picked for the entire model to investigate changes in velocity along the steps. This point will indicate the performance of aeration efficiency with the existing design. Future improvements can then be applied based on the computed values from these points. The approximate locations of points of interest are picked within the steps and are illustrated by Figure 8 as below. 


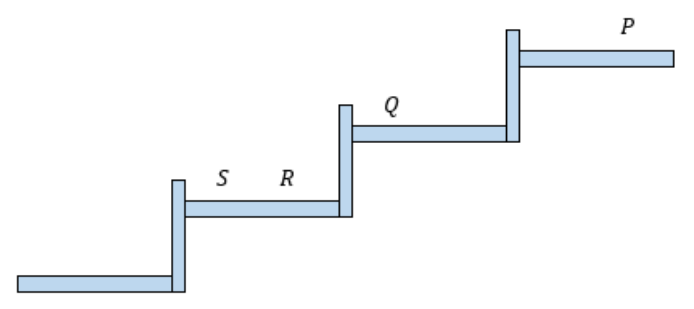

Figure 8: Points of interest located at each step for model

The points of interest and the corresponding velocities can be obtained from PIV image once image calibration is completed. Figure 9 summarizes the data obtained from experimental.

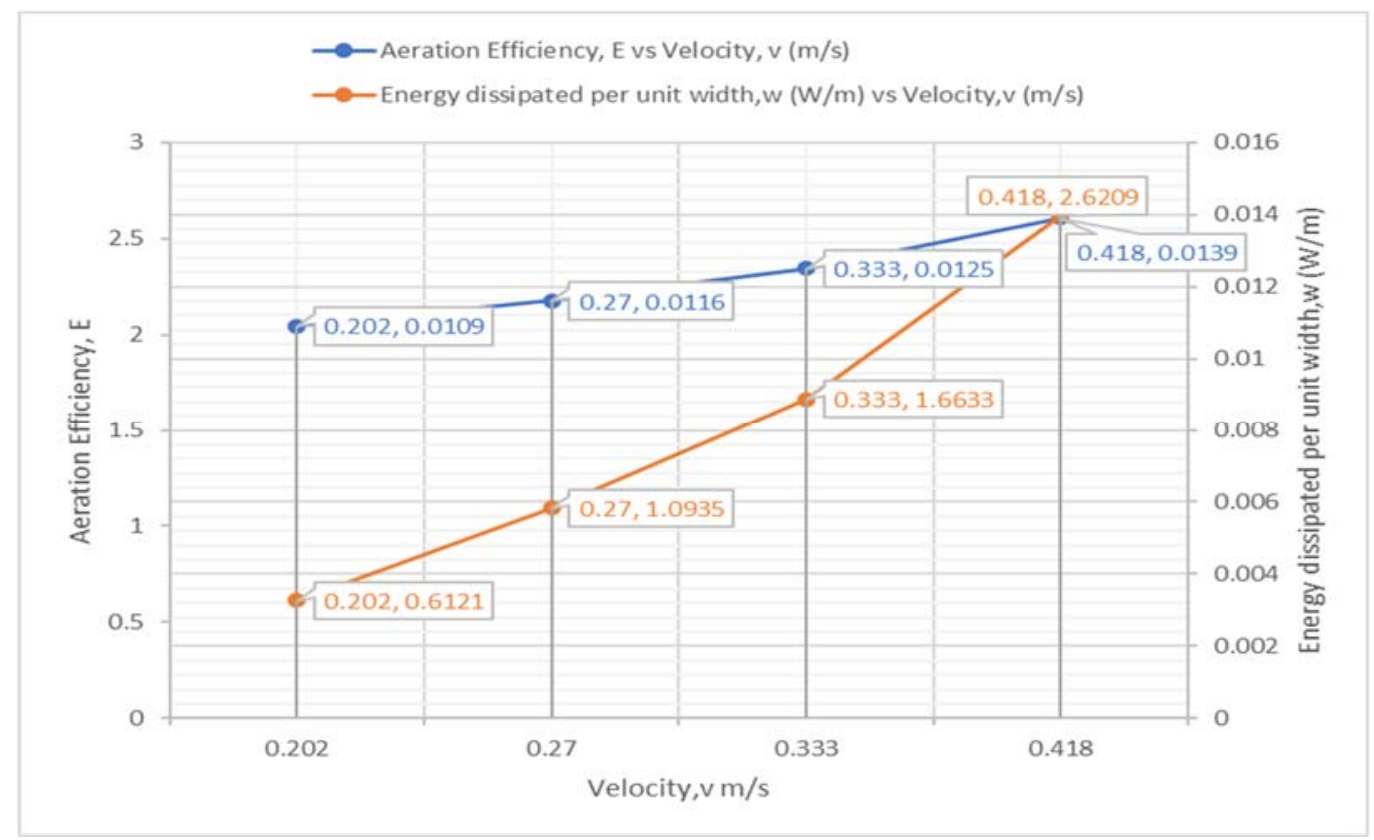

Figure 9: Plotted Graph from data collected

According to figure 9, the aeration efficiency of 0.0139 and a velocity value of $0.418 \mathrm{~m} / \mathrm{s}$ was computed at point $\mathrm{S}$ which is highest compared to point $\mathrm{R}$ with aeration efficiency of 0.0125 and a velocity value of $0.333 \mathrm{~m} / \mathrm{s}$. The results show that the aeration efficiency increases as the velocity increases. These results occur because the velocity increase as the step size increases due to the potential energy from the top of cascade aerator changes into kinetic energy when it goes to the lowest step size. The lowest efficiency occurs at point $P$ with aeration efficiency of 0.0109 and a velocity of $0.202 \mathrm{~m} / \mathrm{s}$ at the top of cascade aerator. This lowest efficiency can be improved by increasing the barrier height to generate higher turbulence flow and swirl effect. Besides that, by increase the size of step also can affect the aerator efficiency due to the velocity increase.

\section{CONCLUSION}

Physical study was performed on a river bank configuration comprising barrier height of $10 \mathrm{~mm}$. The focus of the study was on the flow patterns, velocity and aeration efficiency performance. The stepped configuration showed identical flow pattern with 
nappe flow regime developed, which can be viewed as the discharge of water in a succession of free falling nappes from one step pool to the following. The results also highlighted an increasing of velocity pattern from point $\mathrm{P} \rightarrow \mathrm{Q} \rightarrow \mathrm{R} \rightarrow \mathrm{S}$ with a value of $0.202 \mathrm{~m} / \mathrm{s}, 0.27 \mathrm{~m} / \mathrm{s}, 0.333 \mathrm{~m} / \mathrm{s}, 0.418 \mathrm{~m} / \mathrm{s}$. In terms of the energy dissipation and the aeration efficiency, similar increasing pattern is recorded for points $\mathrm{P}, \mathrm{Q}, \mathrm{R}$ and $\mathrm{S}$ with values of $0.6121 \mathrm{~W} / \mathrm{m}, 1.0935 \mathrm{~W} / \mathrm{m}, 1.6633 \mathrm{~W} / \mathrm{m}$ and $2.6209 \mathrm{~W} / \mathrm{m}$ while for the aeration efficiency with values of $0.0109,0.0116,0.0125$ and 0.0139 respectively. This increasing pattern for velocity, aeration efficiency and energy dissipation indicated the importance of having cascade aerator design that with more height or increased in barrier height since it will promote air circulation thereby increasing the formation of manganese and iron oxides. As a result, cleaner water will be obtained towards the end of the cascade aerator system.

\section{ACKNOWLEDGEMENTS}

The authors would like to acknowledge Universiti Sains Malaysia and Uniten R\&D Sdn. Bhd. for providing the facilities and financial assistance under accounts (304/PMEKANIK/60313052 and U-841).

\section{REFERENCES}

[1] H. Khdhiri, O. Potier, and J.-P. Leclerc, "Aeration efficiency over stepped cascades: Better predictions from flow regimes,” Water Res., vol. 55, pp. 194202, May 2014.

[2] Amador, G. Van der Graaf, M. Sanchez-Juny, J.Dolz, F. Sanchez-Tembleque, J.Puertas, "Characterization of the flow field in a stepped spillway by PIV".

[3] Y. Peltier, B. Dewals, P. Archambeau, M. Pirotton, S. Erpicum, "Pressure and velocity on an ogee spillway crest operating at high head ratio: experimental measurements and validation", $2^{\text {nd }}$ International Workshop on Hydraulic Structures: Data Validation, (2015).

[4] S. Felder, H. Chanson, "Aeration, flow instabilities and residual energy on pooled stepped spillways of embankment dams”, Journal of Irrigation and Drainage Engineering, ASCE, Vol.139, No. 10, pp.880-887.

[5] X. Xie, C. Le Men, N. Dietrich, P. Schmitz, and L. Fillaudeau, "Local hydrodynamic investigation by PIV and CFD within a Dynamic filtration unit under laminar flow," Sep. Purif. Technol., vol. 198, pp. 38-51, 2018.

[6] Q.-Q. Xiong, Z. Chen, S.-W. Li, Y.-D. Wang, and J.-H. Xu, "Micro-PIV measurement and CFD simulation of flow field and swirling strength during droplet formation process in a coaxial microchannel," Chem. Eng. Sci., vol. 185, pp. 157-167, Aug. 2018.

[7] P. Guenther, S. Felder, H. Chanson, "Flat and Pooled Stepped Spillways for Overflow Weirs and Embankments: Cavity Flow Process, Flow Aeration and Energy Dissipation”, (2013).

[8] Amador, M. Sanchez- Juny, J. Dolz, "Developing Flow Region and Pressure Fluctuations on Steeply Sloping Stepped Spillways”, Journal of Hydraulic Engineering, 135(12), (2009). 